\title{
Designing First-year Sociology Curricula and Practice
}

\author{
Theda Thomas ${ }^{1}$, Sue Rechter ${ }^{1}$, Joy Wallace ${ }^{2}$, Pamela Allen ${ }^{3}$, Jennifer Clark ${ }^{4}$, Bronwyn Cole ${ }^{5}$, Lynette Sheridan \\ Burns $^{6}$, Adrian Jones ${ }^{7} \&$ Jill Lawrence ${ }^{8}$ \\ ${ }^{1}$ School of Arts, Australian Catholic University, Melbourne, Australia \\ ${ }^{2}$ Faculty of Arts, Charles Sturt University, Bathurst, Australia \\ ${ }^{3}$ Faculty of Arts, University of Tasmania, Hobart, Australia \\ ${ }^{4}$ School of Humanities, University of Adelaide, Australia \\ ${ }^{5}$ Pro Vice-Chancellor (Education), Western Sydney University, Sydney, Australia \\ ${ }^{6}$ School of Humanities and Communication Arts, Western Sydney University, Sydney, Australia \\ ${ }^{7}$ Department of History and Archaeology, Latrobe University, Melbourne, Australia \\ ${ }^{8}$ School of Arts and Communication, University of Southern Queensland, Toowoomba, Australia \\ Correspondence: Theda Thomas, School of Arts, 115 Victoria Parade, Fitzroy, 3065, Australia. E-mail: \\ theda.thomas@acu.edu.au
}

Received: January 17, 2017

Accepted: February 3, 2017 Online Published: March 24, 2017

doi:10.5539/ass.v13n4p1

URL: https://doi.org/10.5539/ass.v13n4p1

\begin{abstract}
Many countries are now specifying standards for graduates in different disciplines, including sociology. In Australia, the Australian Sociological Association (TASA) has developed Threshold Learning Outcomes (TLOs) for sociology to provide the learning outcomes that students graduating with a bachelor's degree in sociology should achieve. These TLOs have encouraged universities to think explicitly about their sociology curriculum in a holistic way. This paper reports on a project that investigated the skills and concepts sociology students need to learn in first year to meet the TLOs by the time they graduate. The project identified the needs of students as they transition from school or work into the study of sociology in first year through a study of literature of first-year pedagogy and a student survey. A workshop was held for sociology that involved 37 academics from 14 universities. The workshop was used to promote a rethink of teaching of sociology in the light of the new TLOs as well as to collect ideas from the participants. The student surveys, workshop ideas and relevant literature were analyzed and synthesized for each TLO to determine what skills and concepts first-year students needed to learn, identify what they might find difficult and propose strategies for teaching. The paper also provides practical ideas for engaging academics with thinking holistically about the sociology curriculum and for teaching and learning sociology in the first year of an undergraduate degree.
\end{abstract}

Keywords: discipline standards, first-year pedagogy, learning outcomes, sociology, threshold concepts

\section{Introduction}

A sociology major in a liberal arts or social science degree is usually made up of an "Introduction to Sociology" subject followed by a wide selection of more advanced sociology subjects each covering a different topic. The introductory sociology subject is often used as a service course to other programs or as an elective (Greenwood, 2013). In their first year, students are introduced to the discipline of sociology and what sociologists do, but sociology is a diverse discipline and there is little consensus on what should be taught (Greenwood, 2013; Marshall, 2009). The traditional way of instructing students in an introductory sociology subject is to cover a wide range of topics using passive learning methods (Fujieda, 2009). The introductory sociology textbook will address this range of topics, with multiple concepts for each topic providing an overview of the field. The advanced sociology subjects will then provide greater depth in each of the topics. This method of curriculum development has been criticised as it may prevent students from engaging with sociology in an in-depth fashion from first year (Fujieda, 2009).

In 2012 The Australian Sociological Association (TASA) sponsored a working group that consulted widely with academics, employers and practitioners to establish a set of minimum standards for Sociology graduates. These 
standards were called Threshold Learning Outcomes (TLOs). The agreement on TLOs, while essential, is only the first step, and needs to be supported by whole of program design that scaffolds student learning in a progressive fashion from first year to graduation.

This paper reports on a project undertaken to discover how this complex matter of curriculum design might be undertaken for first-year sociology, as a foundation for a sequenced curriculum that would then unfold in second and third years. The project focused on five key disciplines in the humanities and social sciences, namely: History, Politics, Geography, English and Sociology.

The main research questions posed for sociology were:

i. What skills and concepts do students in sociology need to learn in first year to meet the TLOs by the time they graduate with a major in sociology?

ii. What barriers might there be to first-year sociology students learning those skills and concepts?

iii. What strategies can we use to help first-year sociology students learn the skills and concepts?

This paper provides the context for the study by describing standards and guidelines for designing sociology curricula, paying attention to the threshold learning outcomes (TLOs) for sociology developed in Australia and used in this investigation. The study then addresses the requirements for a first-year sociology curriculum in ensuring that students transition smoothly into their studies at university and become learners and thinkers within the sociology discipline. The methodology used for the study is explained with a focus on the techniques that were used in workshops. The paper then proposes ideas for each TLO for first-year sociology based on the analysis of the literature, the workshops and student surveys. These ideas can be applied to a wide variety of content within the field of sociology.

\section{Background Literature}

\subsection{The Australian Context: Standards for Graduates in Sociology}

The Australian Tertiary Education Quality and Standards Authority (TEQSA) requires that universities externally benchmark and quality assure their disciplines (TEQSA, 2013). In order to meet this requirement, the Australian Learning and Teaching Council (ALTC) facilitated the development of standards for disciplines in the period 2010-2011 through a project called 'Learning and Teaching Academic Standards (LTAS) Project'. The aim of the project as to develop standards for graduates from different disciplines. These standards were called Threshold Learning outcomes (TLOs) and were defined as 'the minimum learning outcomes in terms of discipline specific knowledge, discipline specific skills including generic skills as applied in the discipline, and discipline specific capabilities that a graduate of any given discipline must have achieved' (ALTC, 2011, p.13). The project teams consulted with academics, practitioners and employers to develop TLOs across a wide spectrum of discipline areas including Law, Accounting, History, Geography, Sciences and Creative Arts. While agreement about this approach to curriculum development and education is not universal, TLOs and other discipline standards offer a flexible framework for what has been identified as the need for sociology academics to explicitly and reflexively consider curriculum issues in sociology (Marshall, 2009).

The ALTC tasked peak discipline groups with developing TLOs for their discipline and TASA took on this responsibility for sociology in Australia (Farquharson, 2013; TASA, 2012). The TASA Executive formed a National Academic Standards Working Group under the leadership of Associate Professor Karen Farquharson. The working group consulted widely across the university sector and the final TLOs were published in 2012 . They are presented in Figure 1 (Farquharson, 2013; TASA, 2012). These learning outcomes are not meant to be prescriptive in terms of content, teaching methods or assessment methods. They allow institutions the freedom to adapt them according to their mission and strategic vision (Farquharson, 2013) and they allow teachers to adapt them according to their own teaching styles and the needs of their classes.

Other countries have also defined standards for sociology or provide guidelines for offering sociology majors. For example, The United Kingdom Quality Assurance Agency (QAA) has created discipline benchmark statements for sociology that include standards for general cognitive skills and abilities; discipline-specific skills and abilities and transferable skills (QAA, 2007). They also include a typical standard and a threshold (or minimum) standard, which are similar to the standards used in Australia. The Tuning Project in Europe has defined agreed competences and learning outcomes for various disciplines (Tuning, n.d.) but, at this time (August 2016), they have not addressed the discipline of sociology. In the United States, the American Sociological Association (ASA) report, 'Liberal Learning and the Sociology Major', (released in 1991 and updated in 2004) offers guidance for designing and evaluating undergraduate sociology curricula that provide students with the depth required for a sociology major (McKinney, Howery, Strand, Kain \& Berheide, 2004). 


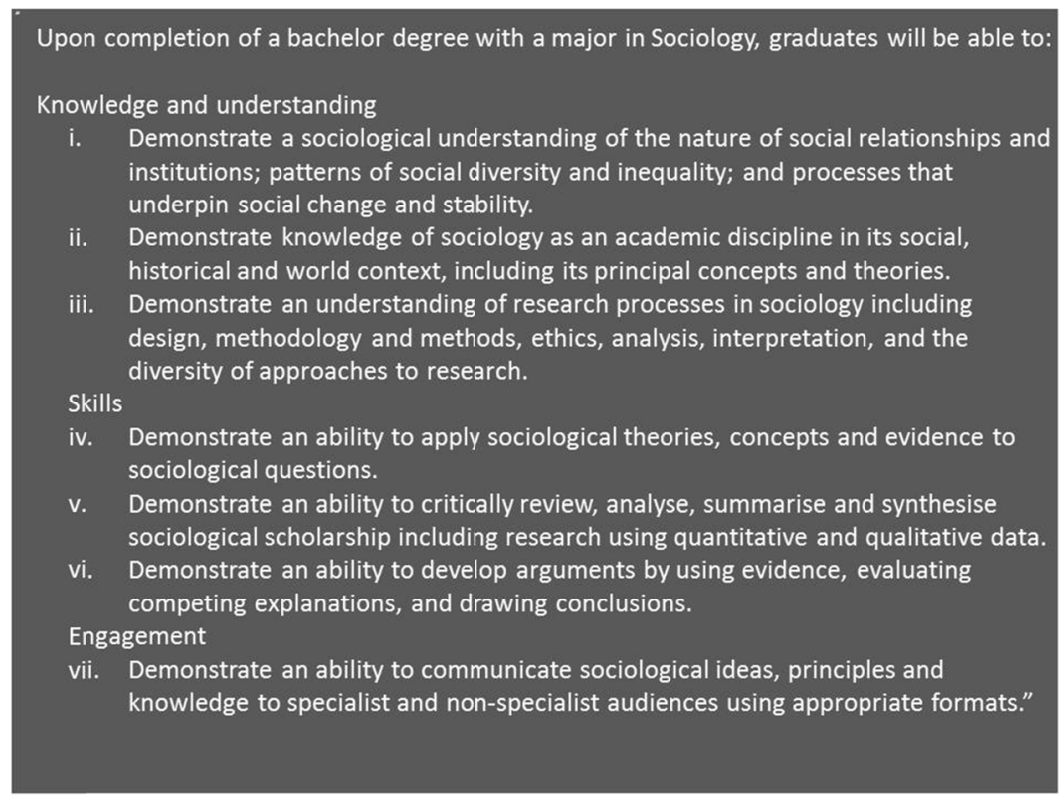

Figure 1. TLOs for Sociology (TASA, 2012, p. 6)

While the terminology might be different in different countries, there is a shared understanding that the sociology major must have sufficient depth and range to allow the cumulative development of students' learning as they move from first year to graduation. This paper focuses on the TLOs for sociology as defined in Australia and the skills and concepts students need to learn at first year to facilitate their thinking and learning so they meet the TLOs by the time they graduate.

\subsection{First-year Learning and Learners in Sociology}

When designing a first-year curriculum, academics need to consider what first-year students should learn so that they can meet the TLOs by the time they graduate; the needs of a first-year student as they transition into university; and the requirement to introduce students to ways of thinking and learning in the discipline of sociology. Bovill, Bully and Morss (2011) suggest that designers of first year curricula for sociology should consider where students are starting from, where they are going, and what the intended outcomes are for the first year. Greenwood (2013) propose that sociology teachers should ask six questions about their students before they design their courses: who their students are; what characteristics they might have that would enhance or be a barrier to their learning; why their students are choosing sociology and what they want to learn; what students aspire to academically or career wise and how their students could use what they are being taught in their lives.

Kift, Nelson and Clarke (2010) suggest a whole-of-university approach to transition pedagogy and see curriculum as comprising the entire academic, social and support system that makes up the student experience. This paper, however, focuses on the part that first-year sociology subject/s can play in transitioning students into university and becoming effective learners of sociology.

According to Tinto (2012), first-year curriculum design and classroom practice should help students to develop a sense of belonging both within the university and as learners in their discipline. A variety of authors have recognised the importance of collaborative learning experiences, active engagement and assessment in motivating first year students and enhancing their social and academic experience of the first year at university (Bovill et al., 2011; Nicol, 2009; Tinto, 2012). But engagement is not enough according to Nicol (2009); students also need to be empowered to become independent learners, critical thinkers and effective learners within the discipline community. The sociology curriculum should include sequential learning experiences that allow students to develop their ability to study in depth and become 'increasingly independent and knowledgeable members of the community of discourse in sociology.' (Berheide, 2005, p.4). Kift (2009) proposes that these experiences should start in first year by giving detailed guidance to students to facilitate their learning and being explicit about the teaching of skills and methodologies, then gradually removing that scaffolding and challenging students to meet their potential and empower them as learners within the discipline (Nicol, 2009).

Bovill et al. (2011) suggest that it is important to consider each student's background and aspirations and what we want them to achieve by the end of first year. This is particularly relevant in a discipline like sociology according to Fujeida (2009) as its focus on social structures like class, race and gender and how they shape 
human behaviour, will personalise many of the issues for students.

\subsection{Threshold Concepts and Signature Pedagogies in Sociology}

The TLOs are intended to encapsulate the key concepts and skills that sociology students should master by the time they graduate. The goal of the project described in this paper was to 'unpack' these TLOs for the purposes of developing curricula that foster the development of the TLOs cumulatively across the three-year major. Meyer and Land (2003) use the term 'threshold concepts' to describe the concepts that are key to understanding a particular discipline or theory. They see these as transformative, integrative and troublesome. They are transformative in that once a student grasps the key concept they are then able to think in the discipline context in a more mature way, leading to a change in the students' personal or professional identity (Land \& Meyer, 2006). They are integrative in that they can change how students view other disciplines or how they integrate their learnings with their existing knowledge. They are troublesome in that they are often challenging and can sometimes be difficult to grasp initially.

So, what are these threshold concepts (for the purpose of this discussion 'concepts and skills' is more appropriate) for sociology and how should we teach them? In a 2007 survey of American discipline and teaching leaders and a comprehensive survey of then-current relevant literature, Persell, Pfeiffer and Syed (2007) identified nine key areas when considering the question 'what should students understand after taking Introduction to Sociology?' These areas were:

i. thinking sociologically (using the sociological imagination);

ii. understanding the scientific nature of sociology;

iii. being able to apply complex and critical thinking in learning to evaluate, use evidence and ask questions;

iv. recognising the centrality of inequality and social stratification;

v. developing a sense of sociology as a field;

vi. understanding how ideas are socially constructed;

vii. recognising the relationship between sociology and other social sciences;

viii. applying their learnings in sociology to the real word; and

ix. understanding the importance of key social institutions in society.

Additional themes included cross-cultural and socio-historical awareness (Persell, et al., 2007). The Australian TLOs are consistent with these, as are results in the broader and more recent literature (Fujieda, 2009; Greenwood, 2013; Zipp, 2012). Important themes in the literature also include the need for active engagement with contemporary issues and with research practice as part of the process of learning key sociological theories, evaluating evidence, and undertaking critical reflection (Berheide, 2005; Greenwood, 2012; McKinney et al., 2004; Schwalbe, 2007). Particularly important for students' understanding of sociology is critical self-reflection as they apply the sociological imagination to their own lives. Rusche and Jason (2011) maintain that students will understand sociology better if they 'recognize themselves as actors in social life and not merely as passive students learning these concepts in the abstract' (p. 339). Rusche and Jason (2011) and Schwalbe (2007) provide ideas and examples of how to do this.

A 'signature pedagogy' provides strategies for engaging students in sociology with thinking and learning in the context of the discipline according to Fujieda (2009). Poole (2007) argues that sociology does not have an obvious signature pedagogy in the same way that law uses case studies or engineering uses design projects, but the active engagement of students in contemporary issues, systematic research practice and critical self-reflection, as suggested above, would generally be accepted as good teaching practice in sociology. Poole (2007) emphasizes that, for sociology, learning environments should implicitly and explicitly foster and reinforce students' sociological ways of knowing by, for example, using the perspective of the sociological imagination (Mills, 2000(1959)) or sociological mindfulness (Schwalbe, 2007). Fujieda (2009) proposes a more specific signature pedagogy for sociology: that of teaching theory as a story that was constructed by each theorist, rather than as a set of abstract ideas.

There are other concerns in relation to teaching and learning across the undergraduate years, both generally and specifically in relation to the sociology disciplines. Williams (2005) suggests that when academics and teachers have been studying in their discipline for a long time, the discourse, ways of thinking and discipline 'rules' may have become second nature to them. Such tacit knowledge may make it difficult for them to be explicit in teaching students how to engage with the discourses in the discipline. 
Threshold concepts are often challenging or troublesome, especially initially, and students may not learn them in a linear fashion (Adler-Kassner, Majewski \& Koshnick, 2012; Meyer \& Land, 2003). They may confront students' existing beliefs or their past practices. For example, students in first year must be introduced to the discourses of sociology but these discourses might clash with the discourses that the students experience at home or through the media (Kapp \& Bangeni, 2009). They may also differ from the discourses that students employ in other disciplines, especially if they are taking a general degree like a Liberal Arts degree, Bachelor of Arts or Bachelor of Social Science (Williams, 2005).

One of the challenges to students' learning in sociology is that they may view the discipline as being biased and subjective or a criticism of their own culture or society according to Fujieda (2009). Fujeida proposes that although this could be seen as an obstacle to student learning, it can be used to emphasize their unexamined observations and show them how theoretical approaches can help them understand a topic in a deeper way. Students can be taught to analyse their own dispositions and evaluate their own perceptions and biases. Adler-Kassner, Majewski and Koshnick (2012) support this by suggesting as learners become more proficient, they should also develop their metacognition of what they know, how they know it and how they can apply it.

\section{Project Methodology}

\subsection{Overview of Methodology}

The project methodology had four stages:

i. a literature study was undertaken at the start to identify the skills and concepts that first-year students in sociology were thought to require;

ii. a survey was undertaken of first-year sociology students. One open ended question is relevant for this paper and the results are discussed briefly later;

iii. a workshop was held in November 2013. The workshop had the dual purpose of engaging lecturers with the TLOs and their implications for first year, and of using the expertise of the group to collect ideas for what could be undertaken in first year to prepare students to meet the TLOs on graduation;

iv. a working group of three academics who had participated in the workshop and had been consulting throughout the project with the project team then brought the ideas from the literature study, student survey and workshop together to formulate the website. Each TLO was expanded to answer the research questions identifying what students needed to know and be able to do; what barriers there might be to their learning, and what strategies could be used to facilitate that learning. Further literature was consulted to expand on the ideas collected in the workshop.

Ethics approval for the collection of data in the project was obtained through the Australian Catholic University Research Ethics Committee (ID 2013 49V) and accepted by the ethics committees for the six other universities participating in the project.

\subsection{Student Survey}

The student survey was undertaken before the workshop. First year sociology students from 4 of the 7 universities participating in the study were invited to participate in the survey. There were 123 responses. The demographic data is provided in Table 1. The students had completed their first semester in sociology and were at the start of their second semester. Seventy-eight percent of the participants were female. Only 39 percent of students were planning on taking sociology as a major with 26 percent saying that the subject was compulsory for the degree that they were taking.

Table 1. Demographic data

\begin{tabular}{cccc}
\hline Item & Value & $\mathrm{N}$ & Percentage (rounded) \\
\hline Number of students & & 123 & $22 \%$ \\
Gender & Male & 27 & $78 \%$ \\
& Female & 96 & $39 \%$ \\
Studying Sociology & As a major & 48 & $35 \%$ \\
& As a minor or elective & 43 & $26 \%$ \\
\hline
\end{tabular}

A detailed discussion of the survey results is beyond the scope of this paper. One of the open-ended questions is 
relevant in that it informed the further work undertaken on identifying the bottlenecks that students experience in the study of sociology. The question asked students to explain what they found difficult about studying sociology (if anything). An overview of the results for this question is provided in Table 2.

Of the 123 students who completed the survey only 61 answered the question on what they found difficult. The most common issue (mentioned by 31 students) was the difficulty in understanding the different theories and abstract concepts used in sociology. Three students also said that they had difficulty with the terminology. The second most common issue for the students was the amount of reading ( 8 students) and managing their time (4 students). Other difficulties mentioned by only one or two students were that they found some of the issues discussed boring or not of interest to them. Two students said that they were confronted by some of the issues discussed.

Table 2. Difficulties experienced by first-year students studying sociology

\begin{tabular}{|c|c|c|c|}
\hline Item & Value & $\mathrm{N}$ & $\begin{array}{c}\text { Percentage students (Percentage of } \\
\text { the } 61 \text { responses) }\end{array}$ \\
\hline Open ended questions & & 61 & \\
\hline \multirow[t]{6}{*}{ Difficulties } & Understanding theory and abstract concepts & 31 & $25 \%(51 \%)$ \\
\hline & Amount of reading & 8 & $6.5 \%(13 \%)$ \\
\hline & Managing time & 4 & $3.2 \%(6.5 \%)$ \\
\hline & Difficulty with terminology & 3 & $2.4 \%(4.9 \%)$ \\
\hline & Confronted by certain issues discussed & 2 & $1.6 \%(3.2 \%)$ \\
\hline & Issues discussed were boring & 2 & $1.6 \%(3.2 \%)$ \\
\hline
\end{tabular}

\subsection{The Workshop}

A day-long workshop for sociology lecturers was held in November 2013. The workshop had two purposes:

- to engage lecturers with the TLOs and thinking about their implications for first year, and

- use the expertise of the group to gather ideas to answer the three research questions.

There were 37 participants drawn from 14 different universities from across Australia. The demographics of the group are shown in Table 3. Twenty-one participants were from metropolitan universities and 16 were from regional universities. Twenty-eight were lecturers in sociology. Nine participants were not sociologists but had responsibility for curriculum development across multiple disciplines (including sociology).

Table 3. Demographics of participants at the sociology workshop

\begin{tabular}{ccc}
\hline Item & Value & $\mathrm{N}$ \\
\hline Number of participants & & 37 \\
Number of universities & & 14 \\
Type of university & Metropolitan & 21 \\
& Regional & 16 \\
Primary responsibility & Sociology lecturer & 10 \\
& Sociology senior lecturer & 6 \\
& Sociology associate professor & 3 \\
& Sociology professor & 9 \\
\hline
\end{tabular}

The one-day workshop was organized around a number of interactive sessions designed to facilitate the participants' learning of the TLOs and their implications for first year. The workshop also used the participants' expertise to generate and share ideas. This section will focus on the techniques used to collect the ideas related to the three research questions:

\subsubsection{What Bottlenecks Are There to Students Learning in Sociology?}

We used part of the Decoding the Disciplines Methodology (Middendorf \& Pace, 2004) to engage the participants with thinking about the bottlenecks to students learning in first-year sociology and to consider strategies that they might use, as lecturers, to mitigate those bottlenecks. 
First, we asked the participants to identify possible bottlenecks and arrange them into themes. As an example, the bottlenecks that they identified as relating to the theme of applying sociological theories, concepts and evidence to sociological questions were:

- the abstract character of sociological thinking;

- the relationship between theory, methods and real world thinking;

- the language of sociology - students see theory and concepts as jargon; and

- understanding the sociological imagination.

The student survey results were used to triangulate their ideas with the issues that the students raised. We then asked each group to take one of the bottlenecks and follow the next three steps of the Decoding the Disciplines Methodology while thinking about first-year pedagogy principles. These steps were: to identify how an expert would address the bottleneck; how they as lecturers might break down the expert's methods to explicitly teach them to students; and how to design a way of enabling students to practice the methods. The exercise was used to get the participants thinking about strategies that they might use and the threshold concepts students need to learn in sociology, rather than focusing on the content to be taught.

After the workshop the bottlenecks were re-organized into themes related to each of the TLOs and used to identify what students needed to learn in first year and the barriers to their learning. This is discussed later in the paper.

\subsubsection{What do Students Need to Learn at First Year to Put Them on the Path to Meeting TLOs on Graduation?}

Conversation maps (McKenzie, 2010) were used to stimulate ideas about what concepts and skills students needed to learn at first year in sociology in order to meet the TLOs for sociology by the time they graduate. The TLO was placed in the middle of a large sheet of butcher's paper and participants were asked to add to the 'conversation' their ideas about what students needed to learn and how to teach them. They read what was on the paper and then added their thoughts and ideas using arrows to link their ideas to those already on the paper. They could ask questions, propose ideas or comment on what others had put on the paper. Some used smiley faces or ticks to show their support for an idea. Figure 2 provides an example of what part of the conversation map for "TLO4 Demonstrate an ability to apply sociological theories, concepts and evidence to sociological questions" looked like.

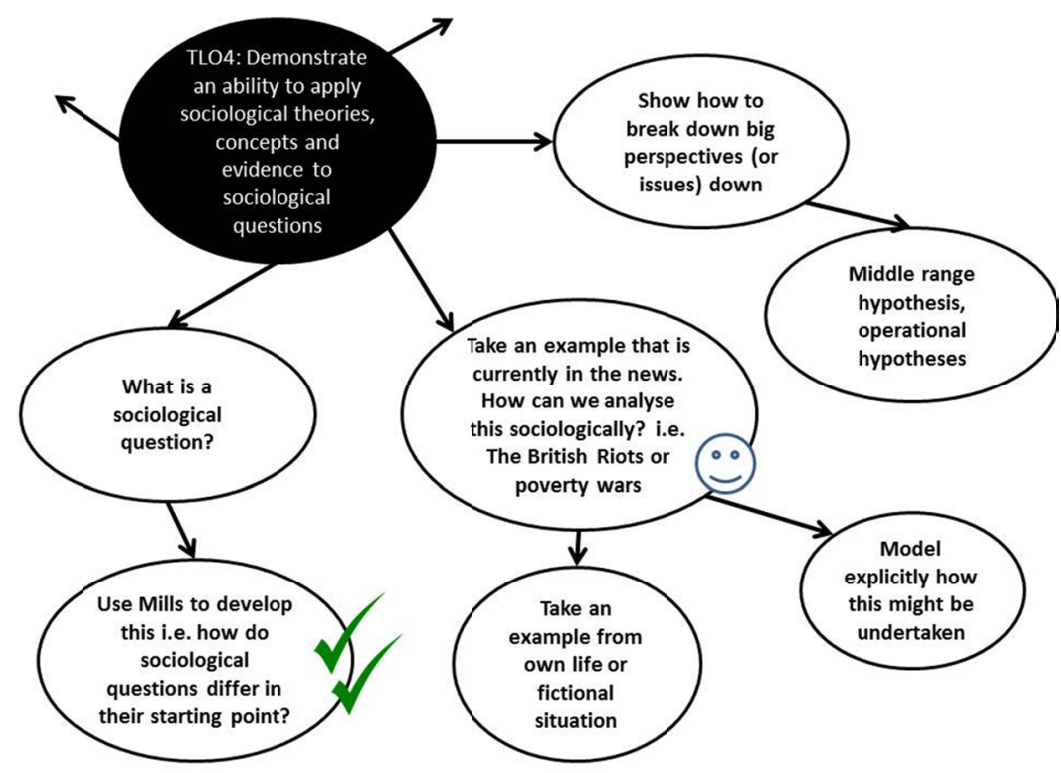

Figure 2. Example of part of conversation map for TLO 4

The conversation maps proved effective in sharing and debating the ideas of the entire group. They also functioned as a way of capturing ideas of a large group, similar to the way a focus group would. The conversation maps were analysed afterwards to provide ideas of what students should know and what strategies could be used. 
The conversation maps were followed by further in-depth discussions on strategies that could be used to help students develop their capabilities towards meeting the TLOs. Participants shared ideas in small groups and then with the larger group. These ideas were collected and placed in a resource bank available on the website.

\section{The Results: Learning in First Year Sociology}

The workshop results were analysed and developed, along with ideas from the literature and the student survey, by a working group of three academics/teachers who had participated in the workshop and had been consulting with the project team throughout the project, providing detailed guidance for each TLO.

It should be stressed that the workshops were intended to inform lecturers about the TLOs, to stimulate explicit reflection about teaching and learning sociology, and to provide material for the website. These results should be regarded as a basis for ongoing reflection, development and revision. Each TLO is discussed in relation to what students need to know and do in order to meet the TLO, and what barriers there might be to their learning. Examples are then given of the teaching techniques. There is some overlap in techniques proposed for the TLOs as one technique could be used to help students develop several skills and understandings. This paper provides an abbreviated version of what is on the website (Sociology, 2015). The project report can be found at Thomas et al. (2015). A framework of questions to ask when undertaking first year curriculum development can be found at Lawrence et al. (2016).

TLO1 Demonstrate a sociological understanding of the nature of social relationships and institutions; patterns of social diversity and inequality; and processes that underpin social change and stability.

First-year students in sociology should develop a basic sociological understanding and engage with debates about social diversity and inequality. In first year we need to link this to what they know, but also open up a way of thinking about social relationships, diversity, inequality and social change that many of them may be unfamiliar with. They should recognize that individuals are influenced by society and that they do not act in isolation. At first year they should be able to identify processes of social change and stability and why societies change.

Students may find it difficult to understand the way in which social relationships influence individual behavior because these influences are invisible" or tacit. Students may have difficulty with debating diversity and inequality because they have had little opportunity to interact or learn about people outside their own class, gender, nationality, religion, ethnic, racial, or sexuality groups. They often have a 'common-sense' understanding of social inequality as the result of individual deficit or 'bad luck', but have had little lived experience of social inequality.

Examples of strategies to help students learn these concepts are:

- Use class participants' own experience (where safe) to explore diverse experiences (Walter \& Butler, 2013).

- Use TV shows such as "Who Do You Think You Are?" to link individuals with social institutions and relationships.

- Have students obtain and compare, and/or interpret data on various aspects of social diversity and inequality (for example income, education, health and welfare from local municipal areas in their own cities and then contrast these with different socio-economic, ethnic populations.)

- Get students to trace global and social relationships by investigating questions like "where do my jeans/shoes/coffee come from?" in order to trace global social and economic relationships. See for example Ben Cushing's (2012) clip on coffee.

- Use concrete case studies of social change and stability to analyse and understand patterns of social change and stability for example:

- Technology-mediated communication, patterns of marriage and sexuality, the enduring levels of unemployment affecting students' job chances, climate change (Hoop, 2012);

- Historical patterns of change - such as changes to the family in the industrial revolution;

- Contemporary case studies of rapid change - such as the rise of fundamentalism or the pro-democracy movements in China and middle east;

- The capacity of an event to influence society (for example a Port Arthur and the gun buy-back scheme in Australia).

TLO 2 Demonstrate knowledge of sociology as an academic discipline in its social, historical and world context, including its principal concepts and theories. 
First-year students should be introduced to the historical and social origin of sociology, how it fits in with other disciplines, and how it is evolving in response to the new contexts and demands of the contemporary world. At first year they should understand the nature of sociology as a discipline and how it differs from other disciplines. They should be able to recognize the way in which sociological practices are ingrained in contemporary society and the importance of context in understanding a social situation.

A barrier to students learning this may be when they see disciplines as 'truths' rather than as human enterprises which develop and change under specific social, cultural and historical circumstances, and which are complementary to other disciplines. It is not always obvious how disciplines such as sociology have contributed, and are contributing, to society.

Examples of strategies to help students learn these skills are:

- Introduce sociology's story complete with its rationale and its unique, pivotal, eccentric people and their contexts.

- Compare this sociology story with stories from other disciplines, cultures, regions, nations and from marginalized groups in the Euro-centric world (Alatas \& Sinha, 2001; Connell, 2007).

- Use the four components of the Sociological imagination - history, culture, structure and critique, as a framework for first year (Willis, 2011), to discuss how and why the classic sociologists thought as they did and whether their ideas are still relevant.

- Discuss the ways in which sociological ideas and practices have become part of the fabric of modern society - e.g. social research input to social policy.

TLO 3 Demonstrate an understanding of research processes in sociology, including design, methodology and methods, ethics, analysis, interpretation, and the diversity of approaches to research.

First-year students should start to build an understanding and skills in sociological research design and methodology. They should be introduced to the purposes of research, some of the major research paradigms, how research is structured and why research is so important to the discipline. While they would not be expected at first year to undertake a full research project they can be introduced to a small variety of techniques and skills that they can apply later in the course.

Students may find research design and methods technical and demanding and may not understand their use and relevance in the real world. If we try to introduce them to too many research paradigms at too detailed a level, this may overwhelm them.

Examples of strategies to help students engage with these issues are:

- Develop students' library and research skills and teach them where to find and how to recognize good quality research in sociology.

- Develop students' capacity to see how pervasive research is about sociological issues and how it is reported and used (e.g. documentaries, radio shock jocks).

- Incorporate case studies of how sociological research is used across a range of public and private sector jobs.

- Use guest speakers/films of quantitative and qualitative research being done in the field across different areas or use your own experience if possible.

- Introduce a topic and provide data. Ask students what the data tells us about the topic.

- Discuss case studies of research ethics abuses to drive home the importance of ethics.

TLO 4 Demonstrate an ability to apply sociological theories, concepts and evidence to sociological questions.

First-year students should be expected to understand the nature of, and engage with, sociological questions. In first year, these could be those about issues of importance to young people. They should be given practice in identifying and creating appropriate sociological questions. Students should be given opportunities to engage with the way in which sociological theories, concepts and evidence are applied and used.

Sociological theories and concepts are difficult concepts for first-year students who may not understand the types of questions sociologists ask and how these differ in their starting point from other approaches. They also may not understand why these sorts of questions are important for society. Students find it difficult to think abstractly about theories and concepts.

Strategies that can be used to help students to grasp these concepts and develop their skills are: 
- Take a contemporary issue such as obesity (Egger \& Swinburne, 2010), gay marriage, mental illness, or (for something lighter) the interest in vampires or Harry Potter in popular culture. Apply and contrast different approaches to each topic, for example: common sense, economic, medical, psychological, political and sociological.

- Introduce theories and concepts gradually based on concrete discussions about students' own lives (see TLO 2) and concurrently with the gradual introduction of research design and methods (see TLO 3).

- Take an example that is currently in the news and model how a sociologist would analyse the event. What different questions would a sociologist ask? How could these questions then be researched? What would constitute evidence? Who could use the results and why?

- Use Mills' work on sociological imagination to help students understand the way sociological questions probe connections between private, individual issues and social issues (Mills, 2000 (1959)).

TLO 5 Demonstrate an ability to critically review, analyze, summarize and synthesize sociological scholarship including research using quantitative and qualitative data.

At first-year students should engage with the scholarship of sociology including qualitative and quantitative research, and start to develop the skills they will need to undertake a critical review or analysis and to summarize and synthesize information and arguments. They should be able to select, analyse and evaluate a research article in terms of its structure, authority, currency, relevance and accuracy.

The first-year student may not know how to read scholarly sociological literature with discrimination, including evaluating ideas, arguments and evidence. They may not be able to summarize/paraphrase and synthesize arguments and evidence. At the first-year level, students will need to learn to apply critical analysis skills alongside learning about research design and sociological theories.

These skills and capabilities will require careful scaffolding through the course. Some of the strategies that can be used in first year are:

- Embed academic literacy skills into the teaching of units and assessments, including library research skills (Ciabattari, 2013).

- Students can be asked to select a research article, summarise it, assess its structure (for qualitative quantitative or mixed methodologies) and evaluate it in terms of its structure, authority, currency, relevance and accuracy.

- Using sociological content, model reading, paraphrasing, summarizing, analysis and synthesis, breaking these down into specific steps for students.

- Ask students take turns reading the first page of text aloud and discuss difficult words and how to work out their meaning.

- In small groups, deconstruct parts of brief, interesting, sociological articles and identify critical, analytic, synthetic elements, including theoretical perspectives and evidence.

- Give students 'common sense' arguments and explanations and ask students to critique these from a sociological point of view.

TLO 6 Demonstrate an ability to develop arguments by using evidence, evaluating competing explanations, and drawing conclusions.

First-year students should be supported to develop confidence and skills in developing their own arguments by using evidence, evaluating competing explanations, and drawing conclusions. Students need help to move beyond their own opinions, cope with multiple perspectives, and gain the confidence to develop and express their own arguments (Massengill, 2011). They need to develop the familiarity and confidence to apply a range of sociological academic literacy skills modelled in scholarly work, to their own practice of developing arguments, using evidence, evaluating competing explanations and drawing conclusions.

Students often lack confidence in presenting their own arguments, thinking that lecturers want their own ideas presented back to them, or thinking they might have the 'wrong' argument. Others may have their own opinion but it is not informed by appropriate evidence and critical analysis.

Strategies that could be useful to help first-year students develop these skills are:

- Show how evidence doesn't always support commonly received points of view on issues.

- Engage students in class debates over real controversies:

- where arguments and evidence need to be offered for differing positions; 
- where students are asked to offer evidence for their own points of view; or

○ where students are asked to take the perspective of those they don't agree with.

- Offer competing evidence and/ or theories about a particular issue and ask students to demonstrate how they would develop a sociological argument to support different interpretations. Explicitly model and scaffold the development of the skills required.

- Transfer to students' own practice through cumulative development of students' own written work, beginning with short assignments highlighting key skills in first year (parallel with comprehension and reading exercises), using sociological content.

TLO 7 Demonstrate an ability to communicate sociological ideas, principles and knowledge to specialist and non-specialist audiences using appropriate formats.

First-year students need to be able to use and explain the terminology of the discipline. They should develop the capacity to conceptualize and explain sociological ideas, principles and knowledge in contexts outside the discipline itself.

First-year students often have difficulty with the terminology used in sociology and this hinders their ability to communicate concepts effectively. They may not appreciate the existence of different audiences and communicative strategies applicable to the different audiences.

Some strategies that can be used to help students develop their communication of sociological concepts are:

- Ask students to write 'reader's comments' from a sociological point of view on current news articles.

- Create short downloadable 'think alouds' by academic staff unpacking sociological texts/ideas and terminology.

- Use peer exchange activities (rather than class presentations) to develop confidence in communication of sociological ideas to a small group.

- Use social media such as blogs, Twitter to encourage students to express and communicate sociological ideas: e.g. using Twitter to comment on programs such as Q and A; writing a sociological blog "one sociological thought per day" (Bassett, 2016).

\section{Conclusions}

Curriculum development in sociology needs to be a social process where lecturers work collaboratively to plan the discipline offerings from first year through to graduation so that they meet the needs of our students and our communities (Greenwood, 2013; McKinney, 2007). We believe that students will benefit if lecturers, teaching into first year, focus on developing student skills and capabilities with a view to them cumulatively attaining a full range of skills and concepts agreed across the discipline as desirable and valuable for sociologists.

The results presented in this paper suggest ways in which the Australian TLOs for sociology can be developed from first year taking into consideration the needs of the first-year student. They are not prescriptive and could be applied to a wide variety of concepts and content within the sociology discipline. We argue that first year lecturers should focus on the skills and concepts we want sociology students to learn at first year and then teach these using the content, rather than focussing on introducing students to a wide variety of content without providing them with the skills that they will need as a sociology student and sociologist.

The techniques used in this study to facilitate first-year lecturers thinking about their curriculum holistically have been tested across five disciplines, including sociology. We believe that these techniques could be useful to universities and disciplines in their curriculum design. An external evaluator for the project has followed up with some of the participants who reported ongoing formal and informal curriculum development at their institutions.

The website (Sociology, 2015) and good practice guides (available on the website) offer a collection of ideas that teachers in sociology can use to stimulate their students' thinking and help them become effective learners in the discipline. The resources are also useful in helping teachers become more explicitly aware of learning and teaching techniques in relation to their discipline. Future research might investigate the effectiveness of these ideas and might also develop assessment tasks across the three years of the degree to measure whether students develop and achieve success by the time they graduate.

\section{Acknowledgements}

Support for this project has been provided by the Australian Government Office for Learning and Teaching. The views expressed in this article do not necessarily reflect the views of the Australian Government Office for Learning and Teaching. 


\section{References}

Adler-Kassner, L., Majewski, J., \& Koshnick, D. (2012). The value of troublesome knowledge: transfer and threshold concepts in writing and history. Composition Forum, 26. Retrieved from http://compositionforum. com/issue/26/troublesome-knowledge-threshold.php

Alatas, S., \& Sinha, V. (2001).Teaching classical sociological theory in Singapore: the context of Eurocentrism, Teaching Sociology, 29(3), 316-331.

ALTC (2011). Resources to assist discipline communities to define threshold learning outcomes (TLOs). Retrieved from http://www.olt.gov.au/resource-library?text=threshold\%20learning\%20outcomes

Bassett, S. (2016). Podology: Sociology. Retrieved from http://www.podology.org.uk/\#/the-impact-of-newmedia/4563962604

Bovill, C., Bulley, C. \& Morss, K. (2011). Engaging and empowering first-year students through curriculum design: perspectives from the literature. Teaching in Higher Education 16(2), 197-209, https://doi.org/10.1080/13562517.2010.515024

Berheide, C. (2005). Searching for structure: Creating coherence in the sociology curriculum, Teaching Sociology, 33(1), 1-15. https://doi.org/10.1177/0092055X0503300101

Ciabattari, T. (2013). Creating a culture of good writing: a cumulative model for teaching writing in the sociology major. Teaching Sociology, 41(1), 60-69. https://doi.org/10.1177/0092055X12462415

Collins, R. (1992). Sociological insight, an introduction to non-obvious sociology. Oxford: Oxford U. Press.

Connell, R. (2007). Southern Theory. Cambridge: Allen and Unwin.

Cushing, B. (2012). Ben Cushing sociology and coffee. Retrieved from https://www.youtube.com/watch?v=KiN M9114Hqs

Egger, G., \& Swinburne, B. (2011). Planet Obesity: How we're eating ourselves and the planet to death. St Leonards, Australia: Allen and Unwin.

Fujieda, E. (2009). Signature pedagogy and the sociological imagination. In R. Gurung, N. Chickand, \& H. A. Sterling (Eds), Exploring signature pedagogies (pp.183-206). Virginia: Stylus.

Greenwood, N.A. (2013). Towards publicly responsive sociology curricula, Teaching Sociology, 41(3), 232-241. https://doi.org/10.1177/0092055X13485026

Hoop, K. (2012). Comte unplugged: using a "technology fast" to teach sociological theory. Teaching Sociology, 40(2), 158-165. https://doi.org/10.1177/0092055X12437973

Kapp, R., \& Bangeni, B. (2009). Positioning (in) the discipline: Undergraduate students' negotiations of disciplinary discourses. Teaching in Higher Education, 14(6), 587-596. https://doi.org/10.1080/13562510903314988

Kift, S. (2009). Articulating a transition pedagogy to scaffold and to enhance the first year student learning experience in Australian higher education, Final Report for ALTC Senior Fellowship Program. Retrieved http://fyhe.com.au/wp-content/uploads/2012/10/Kift-Sally-ALTC-Senior-Fellowship-Report-Sep-092.pdf

Kift, S., Nelson, K., \& Clarke, J. (2010). Transition Pedagogy: A third generation approach to FYE - A case study of policy and practice for the higher education sector. The International Journal of the First Year in Higher Education, 1(1), 1-20. https://doi.org/ 10.5204/intjfyhe.v1i1.13

Land, R. \& Meyer, J. (2006). Threshold concepts and troublesome knowledge: An introduction. In R. Land \& J. Meyer (Eds), Overcoming barriers to student understanding: Threshold concepts and troublesome knowledge (pp.3-18). London: Routledge.

Lawrence, J., Allen, P., Thomas, T., Wallace, J., Clark, J., Jones, A., Cole, B. \& Sheridan Burns, L. (2016). A framework for first year curriculum design and pedagogy: intersecting the Threshold Learning Outcomes, disciplinary knowledge and the first year pedagogy principles, Proceedings of STARS Conference, Perth, Australia 29 June-2 July, 2016, Retrieved from http://unistars.org/papers/STARS2016/12B.pdf

Massengill, R. (2011). Sociological writing as higher-level thinking: assignments that cultivate the sociological imagination, Teaching Sociology, 39(4), 371-381. https://doi.org/10.1177/0092055X11407350

Marshall, H. (2009). Teaching sociology in Australia, Australian Learning and Teaching Council, Retrieved from http://apo.org.au/node/21357 
McKenzie, B. (2010). Conversation Mapping: An Overview. Retrieved from https://www.youtube.com/watch?v=uqwL4k2easU

McKinney, K. (2007). The student voice: sociology majors tell us about learning sociology. Teaching Sociology, 35(2), 112-124._https://doi.org/10.1177/0092055X0703500201

McKinney, K., Howery, C., Strand, K., Kain, E., \& Berheide, C. (2004). Liberal Learning and the Sociology Major Updated: Meeting the challenge of teaching sociology in the 21 century. American Sociological Association. Retrieved from http://www.asanet.org/documents/teaching/pdfs/Lib_Learning_FINAL.pdf

Meyer J., \& Land, R. (2003). Threshold Concepts and Troublesome Knowledge 1 - Linkages to Ways of Thinking and Practising. In C. Rust (Ed), Improving Student Learning - Ten Years On (pp. 412-424). Oxford: Oxford Centre for Staff Learning and Development.

Middendorf, J., \& Pace, D. (2004). Decoding the disciplines: Helping students learn disciplinary ways of thinking. New Directions for Teaching and Learning, 98, 1-12. http://doi.org/10.1002/tl.142

Mills, C. W. (2000(1959)). The sociological imagination. New York: Oxford University Press.

Nelson, K. (2014). Keynote: The First Year in Higher Education - Where to from here?The International Journal of the First Year in Higher Education, 5(2),1-20. https://doi.org/ 10.5204/intjfyhe.v5i2.243

Nicol, D. (2009). Transforming assessment and feedback: enhancing integration and empowerment in the first year. Scottish Enhancement Themes: The First Year Experience. Mansfield, Scotland: The Quality Assurance Agency for Higher Education. Retrieved from http://www.enhancementthemes.ac.uk/pages/ docdetail/docs/publications/transforming-assessment-and-feedback

Poole, G. (2007). Using the scholarship of teaching and learning at disciplinary, national and institutional levels to strategically improve the quality of post-secondary education, International Journal for the Scholarship of Teaching and Learning, 1(2), 1-16. https://doi.org/10.20429/ijsotl.2007.010203

Percell, C., Pfeiffer K., \& Syed A. (2007). What should students understand after taking Introduction to Sociology? Teaching Sociology, 35, 300-314. https://doi.org/10.1177/0092055X0703500401

QAA (2007). Subject benchmark statement: Sociology. Retrieved from http:/www.qaa.ac.uk/en/Publications/Documents/Subject-benchmark-statement-Sociology.pdf

Rusche, S. N., \& Jason, K. (2011). You have to absorb yourself in it: Using inquiry and reflection to promote student learning and self-knowledge, Teaching Sociology, 39(4), 338-353. https://doi.org/10.1177/0092055X11418685

Schwalbe, M. (2007). The sociologically examined life: Pieces of the conversation (4th ed.). N. Y.: McGraw Hill.

Sociology. (2015). In the beginning: Revitalising first year curriculum, Sociology. Retrieved from http:/www.firstyearlearningthresholds.edu.au/sociology/

TASA (2012). Sociology: Threshold learning outcomes. The Australian Sociological Association. Retrieved from https:/www.tasa.org.au/wp-content/uploads/2011/12/threshold-learning-outcomes-for-sociology-final.pdf

Tinto, V. (2012). Enhancing student success: Taking the classroom success seriously, The International Journal of the First Year in Higher Education, 3(1), 1-8. https://doi.org/10.5204/intjfyhe.v2i1.119

Tuning (n. d.). Tuning Educational Structures in Europe. Retrieved from http://www.unideusto.org/tuningeu/subject-areas.html

Walter, M., \& Butler, K. (2013).Teaching race to teach Indigeneity. Journal of Sociology, 49(4), $397-410$. https://doi.org/10.1177/1440783313504051

Williams, K. (2005). Lecture and first year student (mis)understandings of assessment task verbs: Mind the gap, Teaching in Higher Education, 10(2), 157-173. https://doi.org/ 10.1080/1356251042000337927

Zipp, J. (2011). Hans O.Mauksch Address: Teaching for whom? Teaching Sociology, 40(4), $301-311$. https://doi.org/10.1177/0092055X12455650

\section{Copyrights}

Copyright for this article is retained by the author(s), with first publication rights granted to the journal.

This is an open-access article distributed under the terms and conditions of the Creative Commons Attribution license (http://creativecommons.org/licenses/by/4.0/). 